\title{
Changes in the electrophysiological parameters of the posterior intestine of Anguilla anguilla (Pisces) induced by oxytocin, urotensin II and aldosterone
}

B. Baldisserotto ${ }^{1}$ and O.M. Mimura²

\author{
'Departamento de Fisiologia, Universidade Federal de Santa Maria, \\ 97119-900 Santa Maria, RS, Brasil \\ ${ }^{2}$ Departamento de Fisiologia, Instituto de Biociências, Universidade de São Paulo, \\ 05508-901 São Paulo, SP, Brasil
}

\begin{abstract}
Correspondence
B. Baldisserotto

Departamento de Fisiologia UFSM

97119-900 Santa Maria, RS

Brasil

Fax: 55 (055) 226-2423 or 226-1975

E-mail: bernardo@super.ufsm.br

B. Baldisserotto was the recipient of a CAPES fellowship. Publication supported by FAPESP.
\end{abstract}

Received June 12, 1996 Accepted October 15, 1996

\begin{abstract}
In view of the importance of the intestine in the osmoregulation of freshwater fishes, we determined the effects of oxytocin, urotensin II (UII), and aldosterone added to the serosal side of the isolated posterior intestine of the freshwater-adapted teleost Anguilla anguilla on electrophysiological parameters. Oxytocin decreased the short-circuit current (SCC) and transepithelial potential difference (TPD) at concentrations of 1 and $10 \mathrm{mU} / \mathrm{ml}$ (to $50 \%$ and $42 \%$ of control values, respectively), but did not alter these parameters at a concentration of $0.1 \mathrm{mU} / \mathrm{ml}$. UII reduced SCC and TPD at concentrations of $10 \mathrm{nM}, 50$ $\mathrm{nM}$ and $100 \mathrm{nM}$ (to $85 \%$ of control values), but increased these parameters at the concentration of $500 \mathrm{nM}$ (to $115 \%$ of control values). Aldosterone did not alter SCC or TPD at the concentrations tested $(10 \mathrm{nM}$ and $100 \mathrm{nM})$. Oxytocin may open $\mathrm{Na}^{+}$channels in the apical membrane, allowing the flow of $\mathrm{Na}^{+}$to the serosa, reducing SCC and TPD. Should this hypothesis be correct, oxytocin would be important for freshwater adaptation, since it would increase $\mathrm{Na}^{+}$ absorption. The reduction of SCC and TPD in the posterior intestine of A. anguilla induced by UII is evidence that this neurohormone is also important for freshwater adaptation in teleosts. Aldosterone did not show this effect probably due to the lack of receptors in this organ.
\end{abstract}

The intestine of the seawater-adapted teleost Anguilla anguilla absorbs $\mathrm{Na}^{+}, \mathrm{Cl}^{-}$, and $\mathrm{K}^{+}$ions in higher amounts than the intestine of freshwater-adapted eels (1). However, $\mathrm{Na}^{+}-\mathrm{K}^{+}$-ATPase and the coupled $\mathrm{Na}^{+}-$ $\mathrm{K}^{+}-\mathrm{Cl}^{-}$transport, observed in the intestine of seawater-adapted $A$. anguilla, were also demonstrable in the intestine of freshwateradapted eels $(2,3)$. In addition, Trischitta et al. (2) showed that adaptation to seawater or freshwater does not alter the basic transport
Key words - Intestine

- Anguilla anguilla

- Oxytocin

- Urotensin II

- Aldosterone properties of the intestine of $A$. anguilla, and proposed that even in freshwater-adapted fishes this organ could complement the function of the gills in the maintenance of the internal ionic composition. The pattern of stabilization of the transepithelial potential difference of the intestine of this species also suggests that this organ may quickly lead to greater animal adaptation to sea- or freshwater, which is important for the catadromous life of $A$. anguilla (3). 
In view of the importance of the intestine in osmoregulation of freshwater fishes, we determined the effect of three hormones, oxytocin, urotensin II (UII), and aldosterone, on the electrophysiological parameters of this organ.

Immature eels (A. anguilla) weighing 100$200 \mathrm{~g}$ were obtained from a supplier from Aveiro (Portugal) and were kept in a freshwater aquarium at $17^{\circ} \mathrm{C}$, without food for at least three days before use. Transepithelial potential difference (TPD), short-circuit current (SCC) and conductance $(\mathrm{G})$ were measured in the stripped posterior intestine of $A$. anguilla as previously described by Baldisserotto and Mimura (3). The physiological control solution contained 118.5 $\mathrm{mM} \mathrm{NaCl}, 25.0 \mathrm{mM} \mathrm{NaHCO} 3,3.0 \mathrm{mM}$ $\mathrm{CaCl}_{2} .2 \mathrm{H}_{2} \mathrm{O}, 4.7 \mathrm{mM} \mathrm{KCl}, 1.0 \mathrm{mM}$ $\mathrm{MgCl}_{2} \cdot 6 \mathrm{H}_{2} \mathrm{O}, 5.0 \mathrm{mM}$ D-glucose, and 10.0 $\mathrm{mM}$ D-mannitol, $\mathrm{pH} 7.8$, and was gassed with $98 \% \mathrm{O}_{2}-2 \% \mathrm{CO}_{2}$.

The following hormones were tested: oxytocin (Syntocinon, Sandoz), observed for a minimum period of $30 \mathrm{~min}$, UII (Sigma) for at least $40 \mathrm{~min}$, and aldosterone (Aldocorten, CIBA) for at least $2.5 \mathrm{~h}$. All hormones were added to the serosal side. SCC, TPD and G are reported as ratios compared to control values (mean \pm SEM). These fractional values were used for statistical analysis by the Student $t$-test using the Microstat program (Ecosoft, Inc.) which permits the construction of the curve fitting graph (SlideWrite Plus, Advanced Graphics Software Inc.). The minimum significant level was set at $\mathrm{P}<0.05$.

When the posterior intestine was mounted in Ussing-type chambers and bathed on both sides with the same solution, the mucosa was slightly positive. After several minutes, the serosa became negative and reached a steady state after 30-50 min. The SCC flows from serosa to mucosa, corresponding to the flow of negative current from the mucosa to the serosa.

Oxytocin decreased the SCC and TPD at concentrations of 1 and $10 \mathrm{mU} / \mathrm{ml}$, but 0.1 $\mathrm{mU} / \mathrm{ml}$ did not alter these parameters (Figure 1A). There was a significant correlation between the concentration of oxytocin and the decrease in SCC and TPD in the posterior intestine, which could be described by the equations in the legend. Oxytocin did not modify $\mathrm{G}$ (Figure 1A).

UII reduced SCC and TPD when added to the posterior intestine at concentrations of $10 \mathrm{nM}, 50 \mathrm{nM}$, and $100 \mathrm{nM}$. In contrast, UII increased these parameters at $500 \mathrm{nM}$. UII did not alter $\mathrm{G}$ at the concentrations tested (Figure 1B). Aldosterone did not alter SCC, TPD or $\mathrm{G}$ at the concentrations tested (10 $\mathrm{nM}$ and $100 \mathrm{nM}$ ) (Figure 1C).

Oxytocin reduced SCC and TPD in the posterior intestine of $A$. anguilla. Since the neurohormones oxytocin, vasotocin and vasopressin affect water and ion transport across many epithelia, their effects will be discussed here simultaneously. Injection of oxytocin and arginin-vasotocin did not alter the water flow in the intestine of freshwater-adapted Anguillajaponica (4). Vasopressin (pitressin) increased SCC and the flow of water in the colon of Bufo marinus (5). However, this hormone decreased SCC and TPD and increased the absorption of $\mathrm{Na}^{+}, \mathrm{Cl}^{-}$and water in the descending colon of rats (6). Bridges et al. (6) presented two hypotheses for the action of vasopressin: first, this hormone could reduce intracellular $\mathrm{Ca}^{2+}$ because the withdrawal of $\mathrm{Ca}^{2+}$ from the serosa had the same effect, and second, vasopressin could reduce $\mathrm{HCO}_{3}^{-}$secretion, since the absence of this ion reduced the effect of vasopressin on SCC and TPD. The second hypothesis was not compared to the action of oxytocin on the posterior intestine of $A$. anguilla, but 4,4-diisothiocyano-stilbene 2,2-disulfonic acid (DIDS) (3) as well as oxytocin decreased SCC and TPD when added to the serosa (Figure 1A). Vasopressin also stimulated $\mathrm{Na}^{+}$transport from lumen to intracellular medium in the distal cells of the rat nephron (A6 type) by increasing the opening 
of amiloride-sensitive channels (7). The action of oxytocin on the posterior intestine of A. anguilla may be similar; oxytocin may open $\mathrm{Na}^{+}$channels in the apical membrane, allowing the flow of $\mathrm{Na}^{+}$to the serosa, reducing SCC and TPD. Should this hypothesis be correct, oxytocin would be important for freshwater adaptation, since it would increase $\mathrm{Na}^{+}$absorption.

UII concentrations of $10 \mathrm{nM}$ to $100 \mathrm{nM}$ reduced SCC and TPD in the posterior intestine of $A$. anguilla, whereas at a $500 \mathrm{nM}$ concentration these parameters were increased. The intestine of this species absorbs $\mathrm{Na}^{+}, \mathrm{Cl}^{-}$, water (principally), and $\mathrm{K}^{+}$, and the mucosa-serosa flow is higher in seawaterthan in freshwater-adapted animals (1). Consequently, the reduction of SCC and TPD in the posterior intestine of $A$. anguilla induced by UII (if this reduction is due to a lower absorption of ions) is evidence that this neurohormone is important for freshwater adaptation in teleosts. Supporting this hypothesis is the fact that UII increased the absorption of water, $\mathrm{Na}^{+}(20 \mathrm{nM})$, and $\mathrm{Cl}^{-}(10 \mathrm{nM})$ in the anterior intestine of seawater-adapted Oreochromis mossambicus, which is similar to the intestinal pattern of freshwater-adapted fishes of this species (8). UII (100 nM) also depolarized the apical membrane electrical potential difference (with reference to mucosal solution) and increased the fractional resistance of the apical membrane of the posterior intestine of 5\% seawater-adapted Gillichthys mirabilis, but did not change these parameters in seawater-adapted animals (9). Based on these results, together with the fact that UII increased SCC and the mucosa-serosa fluxes of $\mathrm{Na}^{+}$and $\mathrm{Cl}^{-}$in the intestine of this species (5\% seawater-adapted), Loretz et al. (9) proposed that this neurohormone stimulates the cotransporter situated on the apical membrane. In addition, UII inhibited active $\mathrm{Cl}^{-}$efflux in the skin of seawater-adapted $G$. mirabilis and in the opercular membrane of seawater-adapted $O$. mossambicus (10). UII also increased diure-

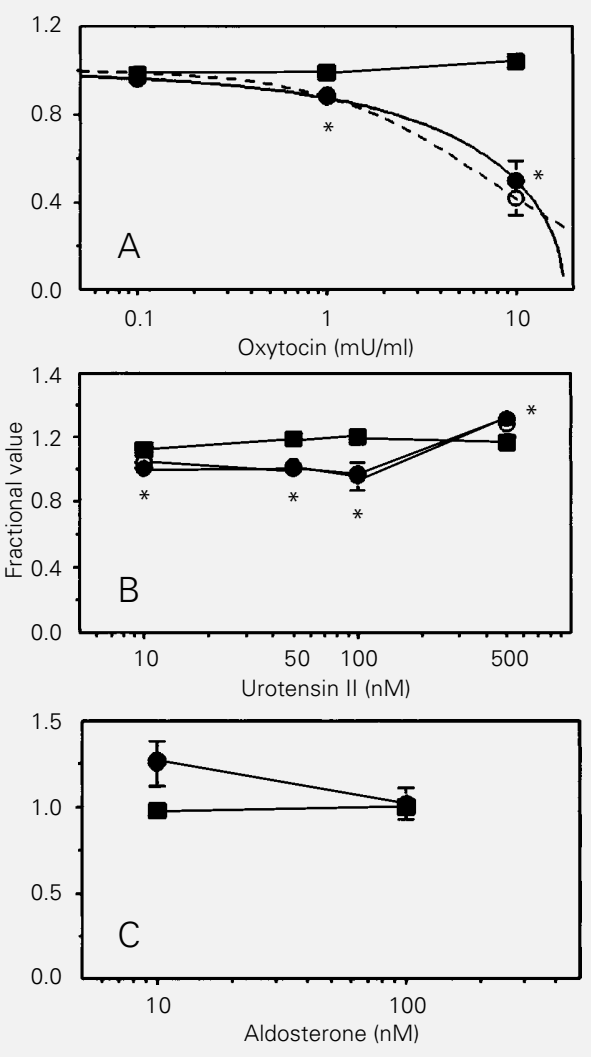

sis in A. japonica (10), which may contribute to the elimination of excess water in freshwater-adapted fishes, and in seawateradapted G. mirabilis transferred to deionized water which showed an increase of UII in the urophysis. However, it is unknown if this increase indicates higher production or lesser liberation of UII (11).

Contrary to this hypothesis is the fact that UII stimulated the reabsorption of $\mathrm{Na}^{+}$in the urinary bladder of G. mirabilis (characteristic of seawater-adapted animals) and inhibited prolactin secretion by the pituitary of $O$. mossambicus (10). Furthermore, seawateradapted Platichthys flesus presented a higher amount of UII in the urophysis than freshwater-adapted fishes (12). Consequently, it is not possible to determine the participation of UII in the regulation of the osmoregulatory organs of teleosts.

Aldosterone did not alter SCC, TPD or G of the posterior intestine of $A$. anguilla (Fig-
Figure 1 - Effect of oxytocin (A), urotensin II (B), and aldosterone (C) on the short-circuit current (SCC), transepithelial potential difference (TPD), and conductance (G) of the posterior intestine of Anguilla anguilla. $\bullet$, SCC O, TPD; $\mathbf{- G}$. Data are reported as means \pm SEM for 8 measurements of each point, with the hormone added to the serosal side. A, Oxytocin. The following equations were fitted to the data: $\operatorname{SCC}(\bullet) \mathrm{y}^{2}=1.002$ $0.237 x^{0.5}\left(R^{2}=0.999, P<0.05\right)$; TPD (0), $y^{-1}=0.998+0.138 \times\left(R^{2}\right.$ $=0.999, P<0.05) .{ }^{*} P<0.05 \mathrm{com}-$ pared to control solution (Student $t$-test). $B$, Urotensin II. ${ }^{*} \mathrm{P}<0.05$ compared to control solution (Student t-test). C, Aldosterone. When error bars are not reported they were less than the size of the symbols. 
ure 1C) or water flow in the intestine of freshwater-adapted A. japonica (4). Aldosterone has been identified in teleosts, but its production in vivo and its function as a mineralocorticoid is not known (13). The dipnoan Lepidosiren paradoxa has an intermediate pattern between teleosts and amphibians: the interrenal gland of this species produces cortisol and aldosterone (14). Aldosterone is found at low concentrations or cannot be detected in plasma of tadpoles, and has a weak effect on $\mathrm{Na}^{+}$retention, but in adult anurans the level of this hormone is usually greater than in mammals (15). The injection of aldosterone into Bufo marinus or its addition to the incubation medium (10 $\mu \mathrm{M}$ ) increased SCC and the absorption of $\mathrm{Na}^{+}$in the isolated colon (16). An increase in the absorption of $\mathrm{Na}^{+}$in the colon was also observed in reptiles and birds (17).

The results of the present study do not eliminate the possibility that aldosterone may act on the intestine of teleosts by affecting ion transport processes. However, our data show that this hormone has noin vitro effect on the posterior intestine of $A$. anguilla, since the time of incubation used in this study (at least $2.5 \mathrm{~h}$ ) was longer than that reported to be necessary to detect stimula- tion of SCC in the colon of B. marinus (16). Since the effect of aldosterone on the rat colon is observed only after several days of in vivo application (18), a similar methodology should be used to determine whether or not aldosterone acts in the intestine of teleosts. Also, it would be interesting to determine whether aldosterone receptors exist in teleosts, since it seems that significant amounts of this hormone are found only in animals with limited water supply (dipnoans, adult anurans, reptiles, birds, and mammals).

We conclude that oxytocin and UII regulate ion transport in the freshwater-adapted A. anguilla, since both neurohormones decreased SCC and TPD in the posterior intestine of this species. Aldosterone did not show this effect probably due to a lack of receptors in the posterior intestine.

\section{Acknowledgments}

The authors thank Drs. Hugo and Karin Gil Ferreira and Dr. Maria da Graça Emílio, Instituto Gulbenkian de Ciência, Oeiras, Portugal, for laboratory facilities, technical assistance, and valuable comments. The authors are also grateful to Vania Pimentel Vieira for a critical analysis of this article.

\section{References}

1. Skadhauge E (1969). The mechanism of salt and water absorption in the intestine of the eel (Anguilla anguilla) adapted to waters of various salinities. Journal of Physiology, 204: 135-158.

2. Trischitta F, Denaro MG, Faggio C \& Schettino $T$ (1992). Comparison of $\mathrm{Cl}^{-}$absorption in the intestine of the seawaterand freshwater-adapted eel, Anguilla anguilla: evidence for the presence of an $\mathrm{Na}-\mathrm{K}-\mathrm{Cl}$ cotransport system on the luminal membrane of the enterocyte. Journal of Experimental Zoology, 263: 245-253.

3. Baldisserotto B \& Mimura OM (1994). Ion transport across the isolated intestinal mucosa of Anguilla anguilla (Pisces). Comparative Biochemistry and Physiology, 108A: 297-302.
4. Hirano T \& Utida S (1968). Effects of $\mathrm{ACTH}$ and cortisol on water movement in isolated intestine of the eel, Anguilla japonica. General and Comparative Endocrinology, 11: 373-380.

5. Cofré G \& Crabbé J (1967). Active sodium transport by the colon of Bufo marinus: stimulation by aldosterone and antidiuretic hormone. Journal of Physiology, 188: 177-190.

6. Bridges RJ, Nell G \& Rummel W (1983). Influence of vasopressin and calcium on electrolyte transport across isolated coIonic mucosa of the rat. Journal of Physiology, 338: 463-475.

7. Marunaka Y \& Eaton DC (1991). Effects of vasopressin and CAMP on single amiloride-blockable $\mathrm{Na}^{+}$channels. American Journal of Physiology, 260: C1071-C1084.
8. Mainoya JR \& Bern HA (1984). Influence of vasoactive intestinal peptide and urotensin II on the absorption of water and sodium chloride by the anterior intestine of the tilapia, Sarotherodon mossambicus. Zoological Science, 1: 100-105.

9. Loretz C, Howard ME \& Siegel AJ (1985) Ion transport in goby intestine: cellular mechanism of urotensin II stimulation. American Journal of Physiology, 249: G284-G293.

10. Larson BA \& Bern HA (1987). The urophysis and osmoregulation. In: Pang PKT \& Schreibman MP (Editors), Vertebrate Endocrinology: Fundamentals and Biomedical Implications. Academic Press, San Diego, 143-156. 
11. Larson BA \& Madani Z (1989). Acclimation to different salinity affects urotensin immunostaining in the caudal neurosecretory system of Gillichthys mirabilis. Annals of the International Symposium on Comparative Endocrinology, May 14-20, Malaga, Spain, European Society of Comparative Endocrinology, P-201.

12. Arnold-Reed DE, Balment RJ, McCrohan CR \& Hackney CM (1991). The caudal neurosecretory system of Platichthys flesus: general morphology and responses to altered salinity. Comparative Biochemistry and Physiology, 99A: 137143.
13. Nishimura $H$ (1987). Role of the reninangiotensin system in osmoregulation. In: Pang PKT \& Schreibman MP (Editors), Vertebrate Endocrinology: Fundamentals and Biomedical Implications. Academic Press, San Diego, 157-187.

14. Kime DE (1987). The steroids. In: ChesterJones I, Ingleton PM \& Phillips JG (Editors), Fundamentals of Comparative Vertebrate Endocrinology. Plenum Press, New York, 3-56.

15. Gorbman A, Dickhoff WW, Vigna SR, Clark NB \& Ralph CL (1983). Comparative Endocrinology. John Wiley \& Sons Inc., New York.
16. Dawson DC \& Curran PF (1976). Sodium transport by the colon of Bufo marinus: $\mathrm{Na}^{+}$uptake across the mucosal border. Journal of Membrane Biology, 28: 295307.

17. Collie NL \& Hirano T (1987). Mechanisms of hormone actions on intestinal transport. In: Pang PKT \& Schreibman MP (Editors), Vertebrate Endocrinology: Fundamentals and Biomedical Implications. Academic Press, San Diego, 239-270.

18. Foster ES, Zimmerman TW, Hayslett JP \& Binder HJ (1983). Corticosteroid alteration of active electrolyte transport in rat distal colon. American Journal of Physiology, 245: G668-G675. 